\title{
The Effect of Carbon Dioxide Insufflation During Transoral Endoscopic Thyroidectomy via a Vestibular Approach on Internal Jugular Vein Pressure Changes: Is There a Safer Alternative?
}

\author{
Christian Camenzuli, FRCSEd' (D), Pierre Schembri \\ Wismayer, $\mathbf{P h D}^{\prime}$, and Jean Calleja-Agius, $\mathbf{P h D}^{\prime}$
}

Dear Editor,

Transoral endoscopic thyroidectomy via a vestibular approach (TOETVA) is a minimally invasive surgical approach to the thyroid gland which has been shown to be relatively safe but comes with a number of novel complications. ${ }^{1}$

Some studies show that a sudden increase in intrajugular pressure leads to an increase in intra-ocular pressure. ${ }^{2,3}$ These changes are particularly important in glaucoma patients since small changes may have a damaging effect on their vision. ${ }^{4}$ Our group has suggested that using a device to modify the standard TOETVA into a gasless 1 might lead to less changes in intra-jugular pressure.

Three Thiel-embalmed cadavers were operated on. This research was conducted after approval by the University of Malta Ethics Committee. Initially a neocirculation selective to the upper body was developed. A TSD104 A blood pressure transducer (BIOPAC ${ }^{\circledR}$ Systems Inc, Goleta, USA) was used to measure the intrajugular pressures. Readings were taken: (i) with the subplatysmal space developed but straps still closed; (ii) after opening the strap muscles and performing an isthmusectomy; and (iii) after right hemithyroidectomy. Four minute readings were taken with insufflation pressures of $6 \mathrm{mmHg}, 15 \mathrm{mmHg}$ and gasless. The readings were then statistically analyzed using paired t-test analysis.

The mean pressures are presented in Table 1. In all 3 cadavers, insufflation was shown to produce a greater increase in intra-jugular pressures when compared with no insufflation. These differences were reproduced in all of the 3 stages $(P<.0001)$.

As the use of TOETVA increases worldwide, it is important to consider not only the cosmetic outcomes but also the safety profile of the procedure. It is pragmatic to move towards gasless modifications of TOETVA.

\begin{abstract}
Author Contributions
Study concept and design: Christian Camenzuli, Pierre Schembri Wismayer, and Jean Calleja-Agius

Acquisition of data: Christian Camenzuli

Analysis and interpretation: Christian Camenzuli, Pierre Schembri Wismayer, and Jean Calleja-Agius

Study supervision: Pierre Schembri Wismayer and Jean CallejaAgius
\end{abstract}

\section{Declaration of Conflicting Interests}

The author(s) declared no potential conflicts of interest with respect to the research, authorship, and/or publication of this article.

\section{Funding}

The author(s) disclosed receipt of the following financial support for the research, authorship, and/or publication of this article: Endaevour Scholarship Scheme Malta.

\section{ORCID iD}

Christian Camenzuli (D) https://orcid.org/0000-0002-8491-6061

\section{References}

1. Lira RB, Ramos AT, Nogueira RMR, et al. Transoral thyroidectomy (TOETVA): complications, surgical time and learning curve. Oral Oncol. 2020;110:104871.

2. Gao Y-b, Liu Y, Zhang Y, Wang X-s, Cai X. Effect of $\mathrm{CO} 2$ insufflation on intraocular pressure during

'Department of Anatomy, Faculty of Medicine and Surgery, University of MaltaRINGGOLD, Msida, Malta

Corresponding Author:

Christian Camenzuli, Department of Anatomy, Faculty of Medicine and Surgery, Biomedical Sciences Building, University of Malta, Msida MSD 2080, Malta.

Email: christian.camenzuli.04@um.edu.mt 
Table I. Mean pressure difference (in $\mathrm{mmHg}$ ) from baseline recorded at each stage of the procedure using no insufflation $(0 \mathrm{mmHg})$, $6 \mathrm{mmHg}$ and $15 \mathrm{mmHg}$ insufflation pressures respectively.

\begin{tabular}{|c|c|c|c|c|c|c|c|c|c|}
\hline & \multicolumn{3}{|c|}{ Stage i } & \multicolumn{3}{|c|}{ Stage ii } & \multicolumn{3}{|c|}{ Stage iii } \\
\hline & $0 \mathrm{mmHg}$ & $6 \mathrm{mmHg}$ & $15 \mathrm{mmHg}$ & $0 \mathrm{mmHg}$ & $6 \mathrm{mmHg}$ & $15 \mathrm{mmHg}$ & $0 \mathrm{mmHg}$ & $6 \mathrm{mmHg}$ & $15 \mathrm{mmHg}$ \\
\hline Cadaver I & .39 & 2.39 & 9.49 & 2.01 & 4.89 & 9.49 & 1.32 & 5.79 & 6.85 \\
\hline Cadaver 2 & -.04 & 2.84 & 10.9 & 5.89 & 8.92 & 10.69 & -.06 & 4.06 & 9.91 \\
\hline Cadaver 3 & -.38 & 5.76 & 8.27 & .73 & 3.06 & 6.84 & -1.32 & 4.87 & 11.67 \\
\hline
\end{tabular}

endoscopic thyroidectomy. Chin J Modern Oper Surg. $2012 ; 4: 35-37$.

3. Kim JA, Kim JS, Chang MS, Yoo YK, Kim DK. Influence of carbon dioxide insufflation of the neck on intraocular pressure during robot-assisted endoscopic thyroidectomy: a comparison with open thyroidectomy. Surg Endosc. 2013; 27(5):1587-1593.

4. McMonnies C. An examination of the hypothesis that intraocular pressure elevation episodes can have prognostic significance in glaucoma suspects. J Opt. 2015;8(4):223-231. 